\title{
A review on the performance of the underground tunnels against blast loading
}

\author{
Kasilingam Senthil ${ }^{* 1}$ iD, Muskaan Sethi ${ }^{1}$ iD, Loizos Pelecanos ${ }^{2}$ iD \\ ${ }^{1}$ Dr BR Ambedkar National Institute of Technology, Department of Civil Engineering, Jalandhar, Punjab, \\ India \\ ${ }^{2}$ University of Bath, Department of Architecture and Civil Engineering, Bath, United Kingdom
}

\begin{abstract}
The tunneling system has become an important part of the present infrastructure system in all over the world. Therefore, it has become important to ensure the safety of the tunnels against any type of man-made blasting activities or other accidental blasting occurrence. In order to evaluate the performance of the tunnels against blast loading, a detailed review is carried out. Based on the review in the last couple of decades, the various parameters such as tunnel lining materials, tunnel shapes, tunnel lining thickness, tunnel burial depth, charge weight and standoff distance are high influences on the performance of underground tunnels against blast loading. It was observed that the tunnel roof and the tunnel wall center are most vulnerable to the blast loads. Also, it was found that more of the tunnel lining thickness results in lesser deformation at the tunnel roof and the tunnel wall center. The increase in the burial depth of the tunnel would reduce the extent of damage to the tunnel caused by effects of surface blast loading. The stiffness and strength of the ground media may be enhanced against the effects of blast loading by grouting measures. The studies revealed that the lining materials possessing blast waves absorbing properties can be best suited to be used in tunnel linings. Further, it was observed that more damage was caused to the tunnels due to the magnitude of the charge weight. An increase in the blast load causes a significant increase in the fracture area, residual stress and lateral displacement caused to the tunnel by the action of blast load. The standoff distance of the blast load from the tunnel also plays a significant role in the damage of the tunnel. More is the distance between the charge and the tunnel, lesser damage caused to the tunnels. In addition to that, the lining thickness was predicted and the trend was calibrated and fitted logarithmically with the available results. Based on the observation from the literature, it is concluded that the use of a single lining material in the tunnel against blast loading was studied predominantly in the couple of decades. Further, the performance of the tunnels in combination of different tunnel lining materials against blast loading was found limited. The influence of barriers to save the underground tunnels against blast loading was found limited.
\end{abstract}

\section{Keywords}

Tunnel lining materials; Tunnel shapes; Tunnel lining thickness; Burial depth

Received: 30 December 2020; Accepted: 23 February 2021

ISSN: 2630-5763 (online) (C) 2021 Golden Light Publishing All rights reserved.

\section{Introduction}

From the past many years, tunnels have become an important part of the civil infrastructure system.
The explosions, either through terrorist activities or through any accidental blast of a vehicle carrying explosive material can pose a serious risk to the

* Corresponding author

Email: urssenthil85@gmail.com 
stability of the structures as well as to the lives of people. Hence it is important to study the various aspects of blast loading on the tunnels to ensure their perfect design, use of suitable lining materials, effective lining thickness or suitable burial depth of the tunnels and to ensure the various preventive measures to be adopted in order to minimize the damage at the time of any explosion or blast. Gui and Chien [1] conducted a parametric study for the analysis of tunnel passing below Taipei Shongsan airport, against blast loading. The intensity of blast loading, crater size, dynamic young's modulus, dynamic undrained shear strength and soil damping ratio were considered as different parameters for the analysis. Choi et al. [2] considered various parameters including shape and size of tunnel, charge weight, standoff distance and different types of surrounding ground, in order to study the effect of internal explosion on underground structures. Van Den Berg and Weerheijm [3] studied the extent upto which the provision of an open space in a tunnel can mitigate the blast effects, by considering the blast generated due to the explosion of $50 \mathrm{~m} 3$ LPG vessel. $\mathrm{Hu}$ et al [4] performed numerical simulations to study the response shown by the columns of a double layered and triple span framed subway station against internal blast loading. It was observed that the charge weights causing blast as well as the distance between the point of observation and the detonation point are the dominating factors which affect the response shown by the columns against corresponding blast loading. Liu [5] suggested a mitigation measure by grouting so as to strengthen the stiffness of the ground media surrounding the tunnel in order to reduce the damage caused to the tunnel lining by blast waves. Damluji et al. [6] developed computer code and solution algorithms based on the principle of pressure formulation to predict the coupled soil behavior, while taking into consideration, the problem of internal gas explosion in a reinforced concrete tunnel. William T.Higgins IV [7] developed a constitutive model to simulate high strain behavior possessed by sand and used the same model to analyze the underground tunnels subjected to the effects of blast loading. It was observed that the type of sand surrounding the tunnel influenced the stress wave propagation through the ground. Greater plastic strains were expressed by the tunnels placed in Ottawa sand and calibrated with high viscosity parameters, since this sand could show a faster dissipation of stresses over a shorter distance. Jiang and Zhou [8] obtained the characteristics of effective stresses and vibration velocities for the elements at different positions in tunnel linings and surrounding rocks, developed by blast loading. Buonsanti and Leonardi [9] studied through the simulations about the effects of an explosion and fire generation on a railway tunnel having reinforced concrete structure. The tension generated in the structure, as an effect of blast overpressure or temperature-pressure due to fire was analyzed so as to identify suitable preventive measures. Feldgun et al. [10] studied the state of pressure and displacement of the tunnel lining, when a rigid inclusion is introduced between the source of explosion and the tunnel. Li et al. [11] analyzed the tunnel stability against an explosion generated wave by an adjacent charge tunnel. The peak particle velocity and distribution of stresses were analyzed to evaluate the tunnel stability. Yu et al. [12] studied about the possible collapse of underground structures due to loss of lateral support under the effect of internal blast loading. It was concluded that the possibility of sidewall collapse can be reduced by providing sufficient lining thickness, sufficient reinforcement and proper structural design. Feldgun et al. [13] studied the influence of explosion occurring in a tunnel on an adjacent tunnel and the interaction between the two. Tiwari et al. [14] analyzed the underground tunnels having curved alignment in the longitudinal direction and subjected to internal blast loading. The higher damage and deformation were observed in tunnels having less radius of curvature and appreciable amount of ground heave was also observed in all the analysis. Basirat et al. [15] studied the effects of thickness of sand layer and moisture content on the behavior of underground tunnels against surface blasting. It was observed that the increase in the thickness of the sand layer, reduces high frequency stress waves and hence the 
damage to the tunnel was found reduced. Mitelman and Elmo [16] analyzed the support design of tunnels so that they can withstand the spalling generated due to blast effects. The one-dimensional rock spalling was simulated and compared with analytical spalling equations. The results of $1 \mathrm{D}$ and 2D spalling models were compared with field test results.

Han et al. [17] carried out numerical simulations in order to study about the circular tunnel's failure mechanism when subjected to internal blast loading, considering the charge weight of TNT less than $200 \mathrm{~kg}$. It was observed that the increase in the charge weight causing blast, would appreciably increase the value of lining stress which ultimately leads to the tunnel failure. The failure would firstly occur at a location closest to the blast source and then gets extended further upto $10 \mathrm{~m}$ away from the blast source. Tiwari et al. [18] studied the damage caused to RC lining as well as the rocks surrounding the tunnel subjected to internal blast loading. It was observed that the higher stresses were generated in the rocks when a damage to RC lining occurs. The shock waves show higher attenuation for highly weathered rocks with low modulus whereas ground shock waves were highly propagated in case of less weathered rocks. Tiwari et al. [19] studied that the action of internal blast loading causes a significant amount of deformation on tunnel lining as well as the surrounding soil. It was observed that the extent of deformation is increased with an increase of charge weight and a decrease in the lining thickness. Wang et al. [20] studied the effect of blasting vibrations, generated as a result of expansion in the tunnel excavation, over the adjacent existing tunnel lining. It was observed that the tensile stress and PPV of the arch waist and sidewall of existing lining are higher at the location nearest to the blast source, in comparison to other locations. Liu et al. [21] considered the effect of blast load used for the construction of a new tunnel adjacent to an existing circular highway tunnel named Huanglongshan. The peak particle velocity of the lining structure present in the existing tunnel was studied. It was observed that the peak particle velocity value was higher at the face located infront of the blast source as compared to the face placed behind the blast source. Senthil et al. [22] predicted the response of structural elements against blast loading and calibrated the trend logarithmically with the experimental results. For $100 \mathrm{~kg}$ charge weight, the spall diameter was estimated to be 0.95 $\mathrm{m}$ for reinforced concrete slabs, however the influence diminished for charge weight exceeding $100 \mathrm{~kg}$. Dogan et al. [23] observed that the rebar had insignificant effect on modal behavior of bridge, while determining the effect of rebar on dynamic behavior shown by reinforced concrete bridges.

Based on the detailed literature survey, there are various parameters that affect the performance of the tunnels against blast loading. In particular, the tunnel lining materials, tunnel shapes, effect of tunnel lining thickness and the effect of tunnel burial depth plays an important role in light of safety and stability of the tunnels against blast loading. The performance of the tunnels with different line materials against blast loading is discussed in Section 2. Similarly, the influence of shape of the tunnels against blast loading is discussed in Section 3. The influence of tunnel lining thickness and burial depth of tunnels against blast loading are discussed in Section 4 and 5 respectively. The influence of mass of TNT and standoff distance is also discussed in Section 6 and 7 , respectively.

\section{Influence of lining materials in tunnel}

Ansell [24] studied about the ability of unreinforced shotcrete to be used over the tunnel lining, to withstand the influence of blast loading. The shotcrete lining aging between 1-25 hours was considered. The age of shotcrete did not show much difference in the corresponding performance against blast loading. It was observed that the shotcrete layer could withstand high amounts of particle velocity vibrations, even on the occurrence of fragmentation in the surrounding rock material, within which the explosive was placed. The loss of adhesion at the interface between soil and rocks was considered the major failure mechanism. Archibald and Dirige [25] studied about the support capability 
of spray- on lining materials to inhibit the rockbursts created during mining operations. The use of spraying materials in tunnel lining as a support ensured a significant amount of reduction in damage effects including fracture growth. Musselman [26] investigated the resistance shown by carbon fiber reinforced concrete subjected to blast loading produced by $75 \mathrm{lbs}$ of TNT placed at a standoff distance of 3.2 feet. Wang et al. [27] studied that, incorporating fibers in concrete shows a significant improvement in strength, toughness and failure resistance. The concrete incorporated with $2 \%$ volume of fibers proved to be the best against blast loading, followed by concrete with $1.5 \%$ and $1 \%$ volume fraction of fibers. Zhao et al. [28] proposed a simple method for designing concrete lining in tunnels subjected to explosive detonation on the ground surface or explosion of a projectile penetrating into the ground located adjacent to the tunnel. The proposed method comprises a shotcrete/rockbolt support system, based on the single degree of freedom approach, which prevents the occurrence of spalling due to blast loads. The method follows a step by step procedure and avoids the usage of complex numerical calculations. Liu [29] studied the damage of Cast iron subway tunnels under internal explosions using $75 \mathrm{~kg}$ TNT. The factor significantly influencing the damage of the cast iron lining is the compressibility of the saturated soil, while the effect of the soil-structure interface on the same was considered to be much smaller. The effect of frictional strength between tunnel lining and saturated ground is very negligible on the tunnel lining. It was observed that low grade cast iron failed at tensile stress of $150 \mathrm{MPa}$ with a tensile strain of $0.6 \%$ specific impulse. Hence, these are considered to be the controlling parameters for tunnel lining damage, instead of peak blast pressure. Xia et al. [30] predicted the amount of damage to rocks and the reinforced shotcrete lining structure by the influence of an adjacent excavation blasting, in Damaoshan highway tunnel. It was observed that at the peak particle velocity less than $0.3 \mathrm{~m} / \mathrm{s}$, no failure occurred in the existing tunnel at the rocks-lining interface.
Belal and Hassan [31] studied the effect of blast loading shotcrete lining in terms of displacement and stresses. It was observed that with an increase in the charge weight or tunnel radius, the compressive stresses induced in the shotcrete lining also increases. The lesser is the distance between the tunnel crown and the detonation point, more compressive stresses are induced in the shotcrete lining. Ahmed and Ansell [32] studied the effect on shotcrete from blasting operations during tunneling. It was observed that the shotcrete should be prevented from the blasting effects for the first 12 hours after the shotcreting operation. It was concluded that the additional waiting time can be determined based on the distance and shotcrete thickness. Chakraborty et al. [33] studied on different tunnel lining materials including single layered steel plate, steel fiber reinforced concrete(SFRC), plain concrete slab(PC), sandwiched steel dytherm foam steel panel(SDS) and steel polyurethane foam steel panels(SPS). Among these configurations, PC200 and SFRC 200 slab lining produce less deformation as compared to PC100 and SFRC100 tunnel linings. The SFRC slab linings produce less deformation as compared to PC linings. Also, it was observed that the Tunnel linings made up of steel plates produce less displacement in soil (around 50\% less) in comparison to PC and SFRC slabs. Different thickness in SDS and SPS linings produce almost the same displacement results. The SDS and SPS configuration found more absorbing of the blast waves, hence displacement was low, see Fig. 1.

Zhao et al. [34] studied the blast mitigation effects of the foamed cement base sacrificial cladding used for tunnel structures. The buffer action and cushioning effect are maintained by two main ingredients of the specimen. Those two main ingredients include Expandable Polystyrene Particles and cement matrix. Under low-rate compressive loading, the desirable compressive deformation and plastic performance were shown by the considered foamed cement base material. It was concluded that such a behavior shall be beneficial for the case of blast mitigation when the material behaves as a sacrificial cladding. 


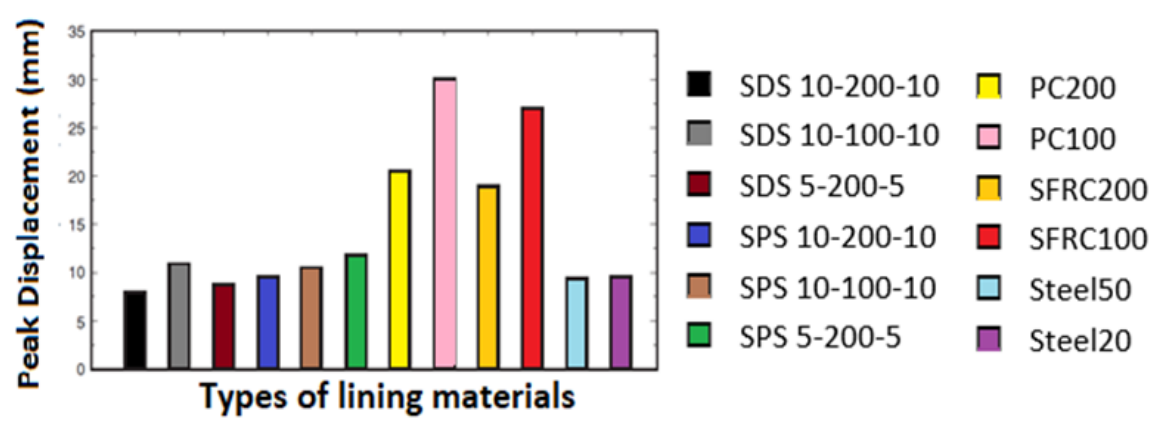

Fig. 1. Peak displacement at soil-lining interface by Chakraborty et al. [33]

Colombo et al. [35] proposed a layered precast tunnel segment solution made from different fiber reinforced cementitious composites. The same is then compared with the traditional lining section made up of reinforced concrete. The performance of fiber reinforced cementitious composites is considered better under internal blast loading. It shows a better performance with regards to both internal and external bending moments as it is characterized through a wider safe zone in $p-i$ diagram. Khan et al. [36] studied the tunnels made up of cast iron lining and subjected to internal blast loading. The blast response of tunnels was found affected significantly by tunnel lining thickness, peak blast pressure and soil and rock elastic modulii. The corresponding results were found less affected by soil and rock dilation angle. It was recommended that, to create a blast resistant tunnel design, an increase in the lining thickness shall be a viable option. De et al. [37] suggested the geofoam material to be placed directly above the structure to prevent it against blast load. It was observed that the measured stresses, strains and pressures at the top of the tunnel found decrease when the protective geofoam barrier's thickness was increased. Zhao et al. [38] performed full scale tests on segmental tunnel lining. To reduce the damage degree of contact area of bolts, trials were made by addition of flexible damping cushions on the joints. When the constraint stiffness of circumferential bolt is reduced, then a compression occurs in the cushion which leads to occurrence of relative moments between the segments. The acting time of force gets prolonged. For the same amount of explosion impulse, amplitude of acting force gets damped, reducing the internal force of segments and bolts. Chen et al. [39] found that as result of gas explosion, the location on the inverted arch that is very close to the hypocenter would be damaged first, followed by the sidewall located near to springing of the arch. It was also observed that at last, longitudinal and circumferential cracks develop on the concrete tunnel lining which divides the lining into different concrete blocks. $\mathrm{Hu}$ et al. [40] proposed a simplified model to study the vibration response of concrete segmental tunnel lining against internal blast loading acting axisymmetrically. It was observed that during the expansion deformation process, stiffness possessed by the joint bolt plays an important role. In case of a contraction phase, all the compression effect is assumed to be taken by the concrete segments.

Amnieh et al. [41] performed dynamic analysis on non-homogenous concrete blocks placed on soil foundation subjected to blast loads. The nonhomogenous concrete blocks were formed using two concrete blocks filled with Barite and reinforced by using $\mathrm{SiO} 2$ nanoparticles, see Fig. 2 . The values of radial, vertical and tangential maximum velocity of the structure had been recorded and placed at different distances from the blast hole, see Table 1. It was further observed that an increase in the percentage of $\mathrm{SiO} 2$ nanoparticles would increase the stiffness of the structure, hence reducing the maximum velocity of the structure by $40 \%$. Dang et al. [42] studied the damage caused to the concrete lining of an existing tunnel, due to the blasting activities used for the construction of a new adjacent tunnel. 


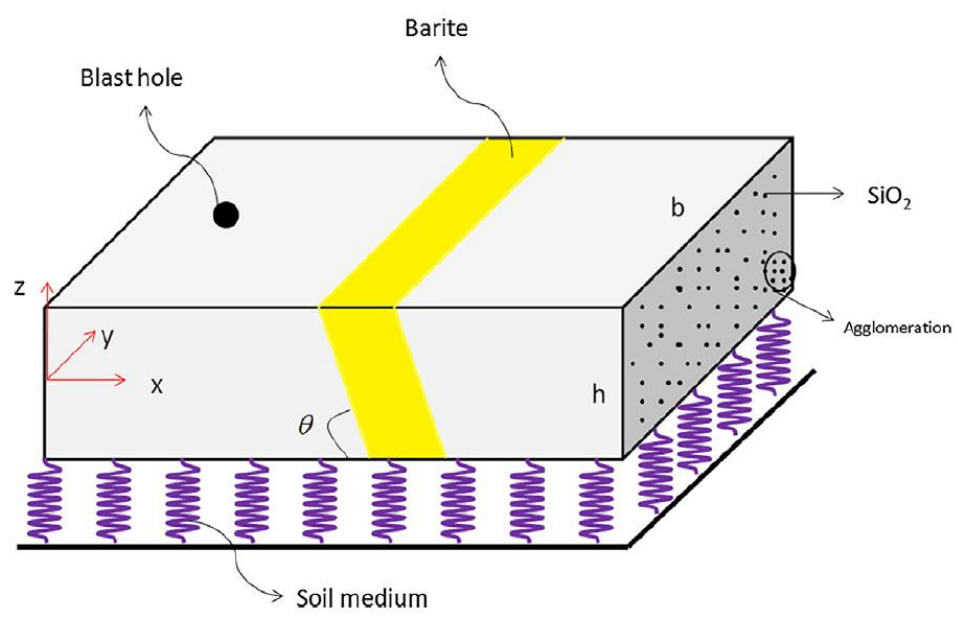

Fig. 2. Schematic representation of non-homogenous concrete blocks filled with barite resting on soil medium and subjected to blast loading [41]

Table 1. Maximum velocity of the structure recorded by blast recorders at different distances from the blast hole [41]

\begin{tabular}{ccccc}
\hline \multirow{2}{*}{ Blast recorder } & $\begin{array}{c}\text { Distance from blast } \\
\text { hole }(\mathrm{mm})\end{array}$ & Radial & Vertical & Tangential \\
\cline { 3 - 5 } & 400 & 128.3 & 125.6 & 92.90 \\
2 & 750 & 83.93 & 79.4 & 47.75 \\
3 & 1650 & 42.40 & 30.72 & 28.38 \\
4 & 2000 & 32.38 & 34.54 & 20.49 \\
\hline
\end{tabular}

It was observed that the tunnel side facing the blast source undergoes greater damage as compared to the face of the tunnel away from the blast source. It was concluded that, more is the distance between the blast source and the existing tunnel face, more is the safety of the concrete lining in the existing tunnel. Li et al. [43] studied the damage on concrete tunnel lining structures due to a gas explosion equivalent to the effect of $2428.9 \mathrm{~kg}$ TNT blast, for a highway tunnel located at Chengdu, in China. It was observed that when the blast shock wave interacts with the lining, a propagation of stress takes place longitudinally and circumferentially along the tunnel until the complete tunnel lining is under the effect of high blast impact loading. The stress is highly concentrated at the sidewall corner, which strengthens up the reflection effect of the blast wave and impart more strength to it. Also, it was observed that the lining portion located near to the blast source experienced a considerable amount of permanent deformation. Chaudhary et al. [44] presented a comparison between the use of conventional and advanced tunnel lining materials subjected to blast loading of $10 \mathrm{~kg}$ TNT. The plain concrete (PC), steel reinforced cement concrete and steel fiber reinforced concrete(SFRC) were considered as conventional materials, see Fig. 3. The advanced tunnel lining materials include Dytherm, Polyurethane, and Aluminium syntactic foam sandwiched panels with steel-foam-steel composites. It was observed that the reinforced cement concrete and steel-aluminium syntactic foam (90 microns)-steel are considered to be suitable as tunnel lining materials.

Majumder and Bhattacharya [45] studied the performance of intermittent geofoam infilled trench as a passive vibration screening method for a reinforced concrete lining tunnel subjected to internal blast loading. 

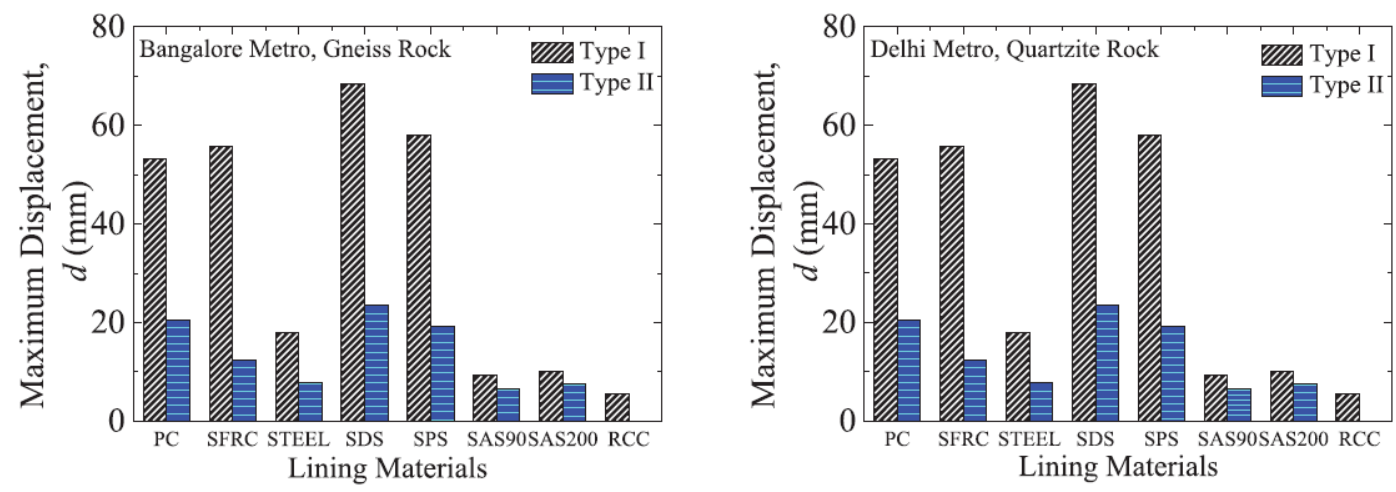

Fig. 3. Maximum displacement for different lining materials [44]

It was concluded that the trench installed with passive vibration screening technique shall help in the reduction of blast waves causing ground vibrations. Kong et al. [46] proposed a new blast resistant technique consisting of composite steel plate lining structures since they possess high tensile resistance and high shear strength. It was observed that the increase in the displacement and velocity on the composite steel plate lining is consistent in accordance to the explosive quantity. Further, it was observed that the influence of blast loading, on the change in the values of displacement, velocity and acceleration at the same reference point on the tunnel lining structure, would increase with the decrease in the distance between the blast source and the reference point. Zhou et al. [47] investigated urban utility tunnels made by Basalt Fiber reinforced polymer bars (BFRP) and steel bars against blast resistance. It was observed that the BFRP bars were found better than the steel bars to reinforce the urban utility tunnels. It is also for the reason that the BFRP bars experience lesser deflections as well as distribution of cracks, as compared to steel bars. Prasanna and Boominathan [48] compared the performance of RCC tunnels with that of cast iron tunnels subjected to internal explosion. It was observed that due to the greater stiffness and density of cast iron tunnels, lesser damage was caused to cast iron tunnels as compared to RCC tunnels (see Table 2).

\section{Influence of shape of tunnels}

Yang et al. [49] studied the dynamic behavior of circular metro tunnels against surface detonation. It was observed that the upper part is considered the most vulnerable in comparison to other parts of the tunnel against the detonation. If a surface explosion contains less than $500 \mathrm{~kg}$ of TNT, then a lining thickness equal to $350 \mathrm{~mm}$ is considered safe for depths more than $7 \mathrm{~m}$. Li et al. [50] observed that a better performance is shown by spherical sandwich shells against air blast loading as compared to cylindrical sandwich shells. Mobaraki and Vaghefi [51] investigated the effect of surface explosion on Kobe box shaped tunnels and compared the results with that of semi ellipse, horse- shoe shaped and circular tunnel. It was observed that circular and horseshoe shaped tunnels show less resistance to demolition than box shaped tunnel, however the semi ellipse tunnel shows more resistance than box shaped tunnel. Uystepruyst and Monnoyer [52] conducted a numerical study of the blast wave shape evolution in rectangular tunnels. When an explosion of condensed materials occurs in a rectangular cross section the blast wave exhibits a 2-D pattern, while the blast waves reveal a 3-D pattern in close proximity to the explosive charge and 1-D pattern far away from explosive charge for square or circular cross section tunnels. Yu et al. [53] investigated square and circular shape's tunnel responses against internal explosion. It was observed that the maximum effective plastic strain response at the critical points (i.e. at the structural corner of the tunnel and center of the top plate) of square tunnels are significantly lower as compared to the circular tunnel. 
Table 2. Peak stress on different tunnel lining materials

\begin{tabular}{lcc}
\hline Literature & Tunnel lining material & Von Mises stress (MPa) \\
\hline Prasanna and Boominathan [48] & Cast Iron & 173 \\
& RCC & Non Uniform Peak stress \\
\hline
\end{tabular}

Koneshwaran et al. [54] studied that ring type segmented tunnels are more flexible for in plane response against surface blasts, however they suffered permanent drifts between the rings. Hexagonal segmented tunnels responded with not much drifts in the longitudinal direction but magnitude of in plane drifts are large which can be hazardous for tunnels. Gao et al. [55] proposed a set of exact solutions for 3D dynamic responses of cylindrical shaped lined tunnels located in saturated soil against internal blast loading. It was observed that dynamic responses including radial displacement, hoop stress, radial stress and pore water pressure decreases sharply in an oscillating manner when the time elapses whereas such responses attenuate exponentially with increasing distances far away from explosion source in both radial and axial direction of tunnel. Soheyli et al. [56] performed an experiment on a box shaped tunnel with reinforced concrete lining subjected to a sub- surface explosion. It was observed that, with an increase in the distance from the source of explosion, the acceleration on the tunnel keeps on decreasing. Zhao et al. [57] studied the response of a cylindrical tunnel against a centric point explosion. An expansion and a contraction phase were observed from the vibrations of the cylindrical shell. During these phases, the axial stress is always outweighed by the maximum hoop stress. As the tensile strength criterion is met by the hoop stress, a failure mode in the form of axial cracks is hence possible, since the concrete possesses lower tensile strength. Mussa et al. [58] considered the effects of surface explosion caused by TNT charge weights of 227, 454, 1814 and $4536 \mathrm{~kg}$ carried within a sedan, van, small delivery truck(SDT) and a container respectively, over an underground box framed tunnel. For blast caused due to small charge weight carried either by a sedan or by a van, little tunnel damage occurs for lining thickness of $250 \mathrm{~mm}$, $500 \mathrm{~mm}$ or $750 \mathrm{~mm}$ at a burial depth equal to $4 \mathrm{~m}$, $6 \mathrm{~m}, 8 \mathrm{~m}$. When the blast occurs due to a greater charge weight carried by a SDT or container, then lining thickness of $250 \mathrm{~mm}$ proves to be inadequate and causes greater damage to the tunnel. The lining thickness equal to $750 \mathrm{~mm}$ along with a burial depth equal to $8 \mathrm{~m}$ proved to be the best against the blast occurrence due to greater TNT charge weight.

Bai et al. [59] examined the vulnerability of rectangular, circular and horseshoe shaped concrete tunnels against the blast loading. It was observed that a rapid breaching of concrete in case of horseshoe shaped tunnels against 400-700lbs of TNT. The circular tunnels can experience a rapid breaching of concrete for the TNT charge between 1300-1500 lbs. Application of additional precast concrete panels or shotcrete layer shall help to avoid the chances of breaching in the tunnel. It was concluded that the breaching area was maximum for horseshoe shaped tunnel, intermediate for rectangular tunnel and minimum for circular tunnel under the influence of $1000 \mathrm{lbs}$ of TNT blast. Dhamne et al. [60] investigated the dynamic response of D shaped tunnel and circular tunnel under blast loading incorporated by using conventional weapons (CONWEP) empirical model. It was observed that the circular shape tunnel was more stable than D shaped tunnel in case of blast loading as it undergoes less deformation observed on the center part of the lining by $1000 \mathrm{~kg}$ blast load of TNT. Mussa et al. [61] assessed the level of damage to an underground box shaped tunnel caused by blast loading using Peak Particle Velocity(PPV) method and single degree of freedom(SDOF) approach. In comparison to the PPV method, better reliability in assessment was obtained by SDOF approach, as the tunnel damage levels were either underestimated or overestimated by the PPV method. Goel et al. [62] carried out finite element analysis for comparison of the damage caused to the tunnel and surrounding soil considering three different tunnel cross sections i.e. arched, circular and rectangular using $100 \mathrm{~kg}$ TNT explosive for saturated and unsaturated soil 
conditions. It was observed that arched as well as rectangular lining experienced $29.56 \%$ and $50.31 \%$ more displacement compared to the circular lining on the top node of the tunnel lining without any change in other parameters, see Table 3. Mandal et al. [63] found that $10 \%$ decrease in peak displacement value for a tunnel with circular cross section because less reflected pressure waves are generated on a circular surface as compared to box shaped and horseshoe shaped surface, facing the explosive. Prasanna and Boominathan [48] found that the largest vertical displacement occurs in case of box shape tunnel as compared to circular and horse- shoe shaped tunnel and a reason that in case of box shape tunnel, the load transfer is controlled by bending that causes a significant reduction in the load carrying capacity. The distribution of plastic deformation for circular tunnels is all around the lining whereas box shape and horseshoe shaped tunnel, the distribution of plastic deformation is concentrated around corners and side walls.

\section{Influence of tunnel lining thickness}

Kamal [64] found that with an increase in lining thickness, the value of plastic strain on the tunnel decreases. It was observed that the displacement at the tunnel crown is the maximum and it decreases with an increase in tunnel lining thickness. It was also observed that the displacement at the invert or spring line are not much affected by a change in tunnel lining thickness. Liew and Wang [65] investigated the performance of a sandwiched panel consisting of steel-concrete-steel configuration against $100 \mathrm{~kg}$ TNT mass placed at a standoff distance of $5 \mathrm{~m}$. It was observed that the thickness of steel plate is important to increase the resistance of steel-concrete-steel panels against blast loading. Ahsan Samiee et al. [66] considered different thickness of polyurea and the effect of polyurea thickness on the performance of steel plates under blast loading. The simulations reveal that when polyurea layer with sufficient thickness is casted on the back face of the plate (The face opposite to that where blast occurs), the bilayer demonstrates superior performance compared to the case of polyurea casted on the front face (The face where the blast occurs).
Table 3. Peak displacement at tunnel for different cross sections [62]

\begin{tabular}{lcc}
\hline \multirow{2}{*}{ Shape } & \multicolumn{2}{c}{ Peak tunnel displacement $(\mathrm{mm})$} \\
\cline { 2 - 3 } & Unsaturated soil & Saturated soil \\
\hline Circular & 13.90 & 9.93 \\
Arched & 16.86 & 12.86 \\
Rectangular & 18.30 & 14.92 \\
\hline
\end{tabular}

The blast mitigation improves as the thickness of the polyurea increases. Tiwari et al. [67] found that the lining displacement can be reduced by $90 \%$ on increasing the value of lining thickness to 550 $\mathrm{mm}$ from $350 \mathrm{~mm}$. Verma et al. [68] concluded that the stress generated in the tunnel lining is strongly influenced by a change in the thickness of the lining material. The stress value increases significantly for lower tunnel lining thickness, hence causing damage to the tunnel. It is important to optimize the lining thickness because, for higher thicknesses, the change in Von Mises stress level is not much significant. Mussa et al. [58] found that the lateral displacement being caused in the tunnel roof and wall center decreases with an increase in the tunnel lining thickness, keeping the value of tunnel burial depth and charge weight to be the same. The lining thickness of $750 \mathrm{~mm}$ proved to be adequate against the blast produced by greater TNT charge carried within a small delivery truck, for all considered burial depth of 4, 6 and $8 \mathrm{~m}$, see Table 4 and 5 . Prasanna and Boominathan [48] found that increasing tunnel lining thickness from 250 to 450 $\mathrm{mm}$, a maximum reduction of $40 \%$ in the displacement of RC lining takes place in case of circular tunnels. Mandal et al. [63] investigated the nonlinear behavior of reinforced concrete constituting the tunnel lining subjected to a surface blast. It was observed that on increasing the tunnel lining thickness from $300 \mathrm{~mm}$ to $600 \mathrm{~mm}$, the value of maximum displacement in the tunnel crown reduced from $43 \mathrm{~mm}$ to $30 \mathrm{~mm}$, see Table 6 . In addition to that, the response of the structural elements was predicted and the trend was calibrated and fitted logarithmically with the results available in the literature. The predicted tunnel lining thickness was $2500 \mathrm{~mm}$ corresponding to peak deflection was found to be negligible, Fig 4. 
Table 4. Displacement of wall center of varying lining thickness

\begin{tabular}{cccccc}
\hline Literature & $\begin{array}{c}\text { Lining thickness } \\
(\mathrm{mm})\end{array}$ & $\begin{array}{c}\text { Burial depth } \\
(\mathrm{m})\end{array}$ & $\begin{array}{c}\text { Displacement of } \\
\text { wall center }(\mathrm{mm})\end{array}$ & $\begin{array}{c}\text { Shape of } \\
\text { tunnel }\end{array}$ & $\begin{array}{c}\text { Tunnel lining } \\
\text { material }\end{array}$ \\
\hline \multirow{2}{*}{ Mussa et al. [58] } & 250 & $4 \mathrm{~m}$ & 125.9 & Box frame & Reinforced concrete \\
& 750 & $4 \mathrm{~m}$ & 0.057 & Box frame & Reinforced concrete \\
\hline
\end{tabular}

Table 5. Reduction in lateral deformation of roof center as per varying lining thickness

\begin{tabular}{cccccc}
\hline Literature & $\begin{array}{c}\text { Lining thickness } \\
(\mathrm{mm})\end{array}$ & $\begin{array}{c}\text { Burial depth } \\
(\mathrm{m})\end{array}$ & $\begin{array}{c}\text { Reduction in } \\
\text { lateral deformation } \\
\text { of roof center }(\%)\end{array}$ & $\begin{array}{c}\text { Shape of } \\
\text { tunnel }\end{array}$ & $\begin{array}{c}\text { Tunnel lining } \\
\text { material }\end{array}$ \\
\hline \multirow{2}{*}{ Mussa et al. [58] } & 500 & 4 & 152.17 & Box frame & Reinforced concrete \\
& 750 & 4 & 566.05 & Box frame & Reinforced concrete \\
\hline
\end{tabular}

Table 6. Maximum Displacement in tunnel crown for $200 \mathrm{~kg}$ TNT

\begin{tabular}{ccccc}
\hline Literature & $\begin{array}{c}\text { Lining thickness } \\
(\mathrm{mm})\end{array}$ & $\begin{array}{c}\text { Max displacement in } \\
\text { tunnel crown for 200 } \\
\mathrm{kg} \mathrm{TNT}(\mathrm{mm})\end{array}$ & $\begin{array}{c}\text { Tunnel lining } \\
\text { material }\end{array}$ & $\begin{array}{c}\text { Shape of the } \\
\text { tunnel }\end{array}$ \\
\hline 300 & 43 & Reinforced concrete & Box shaped \\
Mandal et al. [63] & 450 & 35 & Reinforced concrete & Box shaped \\
& 600 & 30 & Reinforced concrete & Box shaped \\
\hline
\end{tabular}

Table 7. Percentage drop in roof center displacement and wall center displacement with varying burial depth as compared to $4 \mathrm{~m}$ burial depth

\begin{tabular}{|c|c|c|c|c|c|c|}
\hline Literature & $\begin{array}{l}\text { Lining } \\
\text { thickness } \\
\text { (mm) }\end{array}$ & $\begin{array}{l}\text { Lining } \\
\text { material }\end{array}$ & $\begin{array}{l}\text { Tunnel } \\
\text { shape }\end{array}$ & $\begin{array}{l}\text { Burial depth } \\
\text { (m) }\end{array}$ & $\begin{array}{c}\% \text { drop in roof } \\
\text { center } \\
\text { displacement }\end{array}$ & $\begin{array}{c}\% \text { drop in wall } \\
\text { center } \\
\text { displacement }\end{array}$ \\
\hline \multirow{2}{*}{ Mussa et al. [58] } & 250 & $\begin{array}{l}\text { Reinforced } \\
\text { concrete }\end{array}$ & Box frame & 6 & 8.42 & 13.08 \\
\hline & 250 & $\begin{array}{c}\text { Reinforced } \\
\text { concrete }\end{array}$ & Box frame & 8 & 72.7 & 49.04 \\
\hline
\end{tabular}

Table 8. Vertical and horizontal in situ stress value with varying burial depth of the tunnel

\begin{tabular}{|c|c|c|c|c|}
\hline Literature & Tunnel shape & Burial depth (m) & $\begin{array}{l}\text { Vertical in-situ stress } \\
\qquad(\mathrm{MPa})\end{array}$ & $\begin{array}{l}\text { Horizontal in-situ } \\
\text { stress (MPa) }\end{array}$ \\
\hline \multirow{4}{*}{ Li et al. [70] } & \multirow{4}{*}{ Circular } & 0 & 0 & 0 \\
\hline & & 500 & 7.74 & 10.33 \\
\hline & & 1000 & 14.74 & 18.83 \\
\hline & & 1500 & 21.74 & 27.33 \\
\hline
\end{tabular}




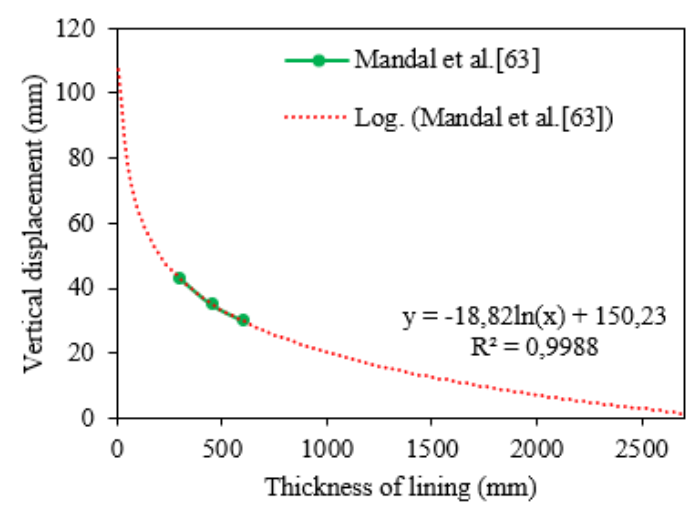

Fig. 4. Deflection in the tunnel corresponding lining thickness extrapolated as logarithmic from the previous study

\section{Influence of burial depth of underground tunnels}

Liu [5] studied the subway tunnels in saturated soft soil subjected to blast loading caused by either 30 or $50 \mathrm{~kg}$ TNT explosives. It was observed that with an increase in the tunnel burial depth, the tunnel confinement is enhanced, which reduces the maximum lining stress under the effect of internal blast loading. Yang et al. [49] analyzed the dynamic responses of the metro tunnels being operated in soft soils. It was observed that the safety of tunnel lining is possible when tunnel depth is more than 7 $\mathrm{m}$ and surface explosion less than $500 \mathrm{~kg}$. Shin et al. [69] investigated the effect of burial depth for the tunnels located in soft rocks. The tunnel crown experienced the maximum blast effect. It was observed that when the burial depth was reduced, the influence of vibrations generated due to blast, caused more damage to the tunnel crown. William T. Higgins IV [7] observed that the distance and time for stress dissipation was more in the case of deeper tunnels. It happened because, with an increase in depth of the tunnel, there is an increase in confining pressure due to which the soil modulus is increased. Mobaraki and Vaghefi [51] suggested that the tunnel burial depth enhances the tunnel resistance against surface blast loads because the energy of compressive waves in the soil decreases with an increase in the depth. The elements located far away from the tunnel roof and wall center experience smaller displacement because low blast pressure is experienced by these elements and they are affected by non-linearity of concrete. Yu et al. [53] found that by increasing the tunnel burial depth, the tunnel confinement is enhanced. The maximum effective plastic strain of the lining under internal blast loading also reduces. When the burial depth is small, low confinement is offered by the ground, which increases the lining strain to a significant extent, ultimately causing tunnel damage. Mussa et al. [58] found that the center displacement of $6 \mathrm{~m}$ and $8 \mathrm{~m}$ burial depth was decreased 8.42 and $72.7 \%$ as compared to $4 \mathrm{~m}$ burial depth, see Table 7. Similarly, significant reduction in the wall displacement was observed when the burial depth increased from 4 to $8 \mathrm{~m}$.

Li et al. [70] suggested that as the burial depth of underground tunnels increases, the tunnel experiences a higher in situ stress level, causing more strain energy to get accumulated at the tunnel periphery, see Table 8. Zaid and Sadique [71] studied the behavior of rock tunnels subjected to blast loading. For charge weight equal to $60 \mathrm{~kg}$, it was observed that occurrence of deformation in the lining decreases by $70-73 \%$ when the burial depth of the tunnel increases from 5 to $7.5 \mathrm{~m}$. Increasing the burial depth from 7.5 to $10 \mathrm{~m}$, causes a decrease in the lining deformation by $23-28 \%$. Hence, more is the burial depth of tunnel, better is the resistance against blast loading.

\section{Influence of varying charge weight}

Tiwari et al. [67] observed that the displacement in the tunnel crown and left side wall is higher for blast produced by $100 \mathrm{~kg}$ charge weight as compared to $25 \mathrm{~kg}$ charge weight. Furthermore, it was observed that the displacement produced at tunnel crown and tunnel side wall were maximum in case of 50 and $100 \mathrm{~kg}$ charge weight respectively. Uystepruyst and Mannoyer [52] varied the charge mass between 1000 to $10000 \mathrm{~kg}$ to study the distribution of overpressure peak possessed by the incident wave. It was observed that $2 \mathrm{D}$ patterns of overpressure peak of Incident wave were similar for every charge mass. Han et al. [17] investigated the interaction between the subway tunnels and the surrounding soil medium for blast produced by 
TNT mass less than $200 \mathrm{~kg}$. A numerical study was conducted to analyze the failure modes of the tunnel lining for varying masses of TNT. Extensive failure occurred in the tunnel by $200 \mathrm{~kg}$ TNT blast due to which the analysis terminated at $9.42 \mathrm{~ms}$. whereas for blast produced by $50 \mathrm{~kg}$ and $100 \mathrm{~kg}$ TNT, the analysis terminated at $15 \mathrm{~ms}$. More fracture area was observed by $200 \mathrm{~kg}$ TNT over the tunnel lining as compared to 50 and $100 \mathrm{~kg}$ TNT blast. Mussa et al. [58] observed that the peak residual displacement occurring in the tunnel roof and wall center to be varying between 4000 and $5000 \mathrm{~ms}$ for blast occurring by sedan and van explosion carrying 227 and $454 \mathrm{~kg}$ mass of TNT respectively. For blast generated by small delivery trucks and containers carrying 1814 and $4536 \mathrm{~kg}$ respectively, the peak residual stress in the tunnel roof and wall center varies between 500 and $2000 \mathrm{~ms}$. Li [72] investigated that, for amplitude of blast load equal to $40 \mathrm{MPa}$ and ratio of wavelength to tunnel diameter between 0.5 and 1.0, no spalling crack was experienced in the incident side of the tunnel. It occurs because the reflected tensile stress wave magnitude was unable to reach the dynamic tensile strength of rock mass. Spalling cracks are visible on the incident side of the tunnel for blast amplitude exceeding $50 \mathrm{MPa}$. Mussa et al. [61] observed an increase in the lateral displacement occurring at the tunnel roof center by gradually increasing the magnitude of explosive charge weight due to an increase in the shock waves intensity. Sevim and Toy [73] studied the response shown by a 2 -storey RC building against 0.1 ton, 0.25 ton and 0.5 ton TNT explosive. The results were recorded in terms of deformed shapes, strain values, pressure value and damage ratio. It was concluded that, with an increase in charge weight, the capacity of the building to absorb the energy released by the blast waves reduces, due to which the damage intensity increases. Senthil et al. [74] studied the acceleration response shown by reinforced concrete tunnels and subjected to varying masses of TNT such as $1.69,2.76$ and $5 \mathrm{~kg}$. It was observed that the value of acceleration increased with an increase in the mass of TNT. Ata et al. [75] studied the effect of blast loading by considering the mass of TNT as
$100,200,300$ and $400 \mathrm{~kg}$. An increase of $64 \%$ of kinetic energy was observed when the charge weight was increased from 100 to $400 \mathrm{~kg}$. Mandal et al. [76] observed an increase in the displacement at tunnel roof center by 94 and $324 \%$ by increasing the charge weight from 250 to $500 \mathrm{~kg}$ and $1000 \mathrm{~kg}$ respectively.

\section{Influence of standoff distance}

Mussa et al. [58] investigated that, decreasing the distance between the explosive and soil would increase the lateral displacement in the tunnel roof and wall center of the tunnel. Toy and Sevim [77] studied the response shown by a RC retaining wall against TNT blast by placing the blast at $5.5 \mathrm{~m}$ and $4 \mathrm{~m}$ away from the wall. It was concluded that the standoff distance of the blast away from the wall had a significant effect on the structural response shown by the wall. Bai et al. [59] observed that the occurrence of spalling or breach damage in the tunnels are related to standoff distance of a specific blast weight. Senthil et al. [74] studied the effect produced by $1.69 \mathrm{~kg}$ TNT on a square box shaped tunnel by varying the standoff distance to $4 \mathrm{~m}, 4.5 \mathrm{~m}$ and $5 \mathrm{~m}$ from the tunnel surface. The value of acceleration on the tunnel showed an increase with a decrease in the standoff distance. Ata et al. [75] observed a reduction of kinetic energy 6.1, 13.3, 21.9 and $44.9 \%$ when the horizontal standoff distance is $1.5,3.0,5.0$ and $10.0 \mathrm{~m}$ respectively from the ground surface. Altunisik et al. [78] observed that the increase in concrete strength of infilled walls causes a decrease in peak pressure and maximum displacement by $22.5 \%$ and $32.16 \%$ respectively, when subjected to blast loading.

\section{Conclusions}

Based on the review in the last couple of decades, various parameters such as tunnel lining materials, tunnel shapes, effect of tunnel lining thickness and the effect of tunnel burial depth are high influences on the performance of underground tunnels against blast loading. The major conclusions were drawn in order to evaluate the performance of the tunnels against blast loading. 
- It was observed that the face of the tunnel in front of the blast source was found more damaged as compared to the face of the tunnel at the rear side.

- It was also observed that the increase in tunnel lining thickness would improve the performance of the tunnels against the blast loading. On increasing the lining thickness to 550 from $350 \mathrm{~mm}$, a significant reduction i.e., $90 \%$ was observed in the tunnel lining displacement.

- On increasing the RC lining thickness from 250 to $450 \mathrm{~mm}$, a reduction of displacement of $\mathrm{RC}$ lining was $40 \%$.

- It was observed that the tunnel lining materials with blast absorbing properties may be suitably used as a protective layer against the blast loading.

- The increase in the magnitude of blast load would significantly increase the intensity of damage to be caused on the tunnel and the surrounding ground media.

- It was observed that, decreasing the distance between soil and the explosive can cause significant damage to the tunnel roof and wall center.

- Also, it was observed that the tunnel walls with lower curvature (like in the case of circular tunnels) show better performance as compared to the tunnel walls with higher curvature (like in the case of square tunnels or horseshoe shaped tunnels).

- It has been observed that an increase in the tunnel burial depth would decrease the extent of damage to be caused to the tunnels by the blast loads.

Based on the observation from the literature, the use of a single lining material in the tunnel against blast loading was studied predominantly in the couple of decades. Further, the performance of the tunnels in combination of different tunnel lining materials against blast loading was found limited. The influence of barriers to safeguard the underground tunnels against blast loading was found limited. Hence, it is concluded that the major parameters affecting the performance of underground tunnels against blast loading include the performance of lining materials, shapes of the tunnels, tunnel burial depth, tunnel lining thickness, magnitude of charge weight and the standoff distance of the blast source from the tunnel. The critical positions on the tunnel against blast loading include the tunnel crown and the tunnel wall center. The performance of such critical positions may be improved by increasing the lining thickness at that point or using a blast absorbing lining material. The confinement of the underground tunnels may be enhanced by increasing the burial depth of the tunnel. The use of a suitable barrier placed between the tunnel and the blast source can compensate for the high intensity of blast affecting the tunnel or the less standoff distance between the tunnel and the blast.

\section{Declaration of conflicting interests}

The author(s) declared no potential conflicts of interest with respect to the research, authorship, and/or publication of this article.

\section{References}

[1] Gui MW, Chien MC (2006) Blast-resistant analysis for a tunnel passing beneath Taipei Shongsan airport - A parametric study. Geotechnical and Geological Engineering 24(2):227-248.

[2] Choi S, Wang J, Munfakh G, Dwyre E (2006) 3D nonlinear blast model analysis for underground structures. GeoCongress 2006:1-6

[3] van den Berg AC, Weerheijm J (2006) Blast phenomena in urban tunnel systems. Journal of Loss Prevention in the Process Industries 19(6):598-603.

[4] $\mathrm{Hu}$ Q, Yu H, Yuan Y (2008) Numerical simulation of dynamic response of an existing subway station subjected to internal blast loading. Transactions of Tianjin University 14:563-568.

[5] Liu H (2009) Dynamic analysis of subway structures under blast loading. Geotechnical and Geological Engineering 27(6):699-711.

[6] Al-damluji OAS, Mahmoud R, Al-nu S, Aldamluji OAS (2010) Mine effects of internal gas explosion on an underwater tunnel roof. International Conferences on Recent Advances in 
Geotechnical Earthquake Engineering and Soil Dynamics.

[7] Higgins WTI. Development of a high strain-rate constitutive model for sands and its application in finite element analysis of tunnels subjected to blast. M.Sc. Thesis. University of Connecticut, 2011.

[8] Jiang N, Zhou C (2012) Blasting vibration safety criterion for a tunnel liner structure. Tunnelling and Underground Space Technology 32:52-7.

[9] Buonsanti M, Leonardi G (2013) 3D simulation of tunnel structures under blast loading. Archives of Civil and Mechanical Engineering 13(1):128134.

[10] Feldgun VR, Karinski YS, Yankelevsky DZ (2013) The effect of an intermediate inclusion in soil on a buried lined tunnel due to a nearby explosion. International Journal of Protective Structures 4(1):1-20.

[11] Li JC, Li HB, Ma GW, Zhou YX (2013) Assessment of underground tunnel stability to adjacent tunnel explosion. Tunnelling and Underground Space Technology 35:227-234.

[12] Yu H, Yuan Y, Yu G, Liu X (2014) Evaluation of influence of vibrations generated by blasting construction on an existing tunnel in soft soils. Tunnelling and Underground Space Technology 43:599-566.

[13] Feldgun VR, Karinski YS, Yankelevsky DZ (2014) The effect of an explosion in a tunnel on a neighboring buried structure. Tunnelling and Underground Space Technology 44:42-55.

[14] Tiwari R, Chakraborty T, Matsagar V (2015) Dynamic analysis of curved tunnels subjected to internal blast loading. Advances in Structural Engineering, Mechanics 1:405-415.

[15] Basirat R, Niri GAD, Izadifard RA (2015) The effect of sand layer thickness and moisture content on underground structures behavior due to surface blasting. Journal of Engineering Research. 3(4):31-42.

[16] Mitelman A, Elmo D (2016) Analysis of tunnel support design to withstand spalling induced by blasting. Tunnelling and Underground Space Technology 51:354-361.

[17] Han Y, Zhang L, Yang X (2016) Soil-tunnel interaction under medium internal blast loading. Procedia Engineering 143(Ictg):403-410.

[18] Tiwari R, Chakraborty T, Matsagar V (2016) Dynamic analysis of tunnel in weathered rock subjected to internal blast loading. Rock
Mechanics and Rock Engineering 49(11):44414458.

[19] Tiwari R, Chakraborty T, Matsagar V (2017) Dynamic analysis of tunnel in soil subjected to internal blast loading. Geotechnical and Geological Engineering 35(4):1491-1512.

[20] Wang W, Yuan Q, Jiang H, Chen PS (2019) Influence and safety control of blasting vibration on existing lining for closely tunnel expansion. IOP Conference Series: Earth and Environmental Science 351(1):012043.

[21] Liu Z, Jiang N, Sun J, Xia Y, Lyu G (2020) Influence of tunnel blasting construction on adjacent highway tunnel: A case study in Wuhan, China. International Journal of Protective Structures 11(3):283-303.

[22] Senthil K, Gupta I, Rupali S, Pelecanos L (2020) A review on the performance of reinforced concrete structures under blast loading. Journal of Structural Engineering and Applied Mechanics 3(4):216-228.

[23] Dogan UU, Altunışık AC, Ergün M (2020) Determination of rebar effect on dynamic characteristics and dynamic behavior of reinforced concrete bridges. Journal of Structural Engineering and Applied Mechanics 3(1):1-17.

[24] Ansell A (2004) In situ testing of young shotcrete subjected to vibrations from blasting. Tunnelling and Underground Space Technology 19(6):587596.

[25] Archibald JF, Dirige PA (2006) Thin, spray-on lining applications for rock-burst, blast and fire damage mitigation. The $41^{\text {st }}$ U.S. Symposium on Rock Mechanics (USRMS): "50 Years of Rock Mechanics-Landmarks and Future Challenges" Golden, Colorado, June17-21, 2006.

[26] Musselman E. Characterizing blast and impact resistance of long carbon fiber reinforced concrete. Ph.D. Thesis. The Pennsylvania State University, 2007.

[27] Wang ZL, Konietzky H, Huang RY (2009) Elastic-plastic-hydrodynamic analysis of crater blasting in steel fiber reinforced concrete. Theoretical and Applied Fracture Mechanics 52(2):111-116.

[28] Zhao PJ, Lok TS, Yin ZQ, Zhou ZL (2010) Simplified design of rock cavern concrete lining to resist shock loading. Journal of Central South University of Technology 17:1087-1094. 
[29] Liu H (2011) Damage of cast-iron subway tunnels under internal explosions. Geo-Frontiers Congress 2011:1524-1533.

[30] Xia X, Li HB, Li JC, Liu B, Yu C (2013) A case study on rock damage prediction and control method for underground tunnels subjected to adjacent excavation blasting. Tunnelling and Underground Space Technology 35:1-7.

[31] Belal AM, Hassan HA (2013) Numerical and rational analysis of shotcrete lining for rock tunnels under effect of explosion loads. International Conference on Case Histories in Geotechnical Engineering 13:0-9.

[32] Ahmed L, Ansell A (2014) Vibration vulnerability of shotcrete on tunnel walls during construction blasting. Tunnelling and Underground Space Technology 42:105-111.

[33] Chakraborty T, Larcher M, Gebbeken N (2014) Performance of tunnel lining materials under internal blast loading. International Journal of Protective Structures 5(1):83-96.

[34] Zhao H, Yu H, Yuan Y, Zhu H (2015) Blast mitigation effect of the foamed cement-base sacrificial cladding for tunnel structures. Construction and Building Materials 94:710718.

[35] Colombo M, Martinelli P, Di Prisco M (2015) A design approach for tunnels exposed to blast and fire. Structural Concrete 16(2):262-272.

[36] Khan S, Chakraborty T, Matsagar V (2016) Parametric sensitivity analysis and uncertainty quantification for cast iron-lined tunnels embedded in soil and rock under internal blast loading. Journal of Performance of Constructed Facilities 30(6):04016062.

[37] De A, Morgante AN, Zimmie TF (2016) Numerical and physical modeling of geofoam barriers as protection against effects of surface blast on underground tunnels. Geotextiles and Geomembranes 44(1):1-12.

[38] Zhao Y, Chu C, Yi Y (2016) Study on an engineering measure to improve internal explosion resistance capacity of segmental tunnel lining structures. Journal of Vibroengineering 18(5):2997-3009.

[39] Chen C, Jiang Y, Yang J, Zheng L, Li Z (2017) Damage mechanism and dynamic analysis of tunnel lining structures under internal blast loading. Civil, Architecture and Environmental Engineering 1:239-246.
[40] $\mathrm{Hu} \mathrm{K}$, Vafeidis A, Chu C, Zhao Y (2018) Vibration of a segment tunnel lining under internal blast loading. Journal of Vibroengineering 20(1):448-458.

[41] Amnieh HB, Zamzam MS, Kolahchi R (2018) Dynamic analysis of non-homogeneous concrete blocks mixed by $\mathrm{SiO} 2$ nanoparticles subjected to blast load experimentally and theoretically. Construction and Building Materials 174:633644.

[42] Dang VK, Dias D, Do NA, Vo TH (2018) Impact of blasting at tunnel face on an existing adjacent tunnel. International Journal of Geomate 15(47):22-31.

[43] Li Z, Wu S, Cheng Z, Jiang Y (2018) Numerical investigation of the dynamic responses and damage of linings subjected to violent gas explosions inside highway tunnels. Shock and Vibration 2018:1-20.

[44] Chaudhary RK, Mishra S, Chakraborty T, Matsagar V (2018) Vulnerability analysis of tunnel linings under blast loading. International Journal of Protective Structures 10(1):73-94.

[45] Majumder M, Bhattacharya S (2019) An alternate arrangement of geofoam blocks and air pocket to mitigate confined blast induced vibration. International Journal of Geotechnical Engineering 15(1):52-65.

[46] Kong D, Xu Y, Song C (2020;) Dynamic response of composite steel lining structure under blast loading. Shock and Vibration. 2020:1-12.

[47] Zhou Q, He HG, Liu SF, Chen XS, Tang ZX, Liu Y, Qiu ZY, Li SS, Wang H, Zhou YZ, Zhou JN, Jin FN (2020) Blast resistance evaluation of urban utility tunnel reinforced with BFRP bars. Defense Technology 17(2):512-530.

[48] Prasanna R, Boominathan A (2020) Finiteelement studies on factors influencing the response of underground tunnels subjected to internal explosion. International Journal of Geomechanics 20(7):04020089.

[49] Yang Y, Xie X, Wang R (2010) Numerical simulation of dynamic response of operating metro tunnel induced by ground explosion. Journal of Rock Mechanics and Geotechnical Engineering 2(4):373-384.

[50] Li W, Huang G, Bai Y, Dong Y, Feng S (2014) Dynamic response of spherical sandwich shells with metallic foam core under external air blast loading-Numerical simulation. Composite Structures 116(1):612-625. 
[51] Mobaraki B, Vaghefi M (2015) Numerical study of the depth and cross-sectional shape of tunnel under surface explosion. Tunnelling and Underground Space Technology 47:114-122.

[52] Uystepruyst D, Monnoyer F (2015) A numerical study of the evolution of the blast wave shape in rectangular tunnels. Journal of Loss Prevention in the Process Industries 34:225-231.

[53] Yu H, Wang Z, Yuan Y, Li W (2015) Numerical analysis of internal blast effects on underground tunnel in soils. Structure and Infrastructure Engineering. 12(9):1090-1105.

[54] Koneshwaran S, Thambiratnam DP, Gallage C (2015) Response of segmented bored transit tunnels to surface blast. Advances in Engineering Software 89:77-89.

[55] Gao M, Zhang JY, Chen QS, Gao GY, Yang J, Li DY (2016) An exact solution for threedimensional (3D) dynamic response of a cylindrical lined tunnel in saturated soil to an internal blast load. Soil Dynamics and Earthquake Engineering 90:32-37.

[56] Soheyli MR, Akhaveissy AH, Mirhosseini SM (2016) Large-scale experimental and numerical study of blast acceleration created by close-in buried explosion on underground tunnel lining. Shock and Vibration 2016:8918050.

[57] Zhao Y, Chu C, Vafeidis A, Li J (2017) Vibration of a Cylindrical Tunnel under a Centric PointSource Explosion. Shock and Vibration 2017:9152632.

[58] Mussa MH, Mutalib AA, Hamid R, Naidu SR, Radzi NAM, Abedini M (2017) Assessment of damage to an underground box tunnel by a surface explosion. Tunnelling and Underground Space Technology 66:64-76.

[59] Bai F, Guo Q, Root K, Naito C, Quiel S (2018) Blast vulnerability assessment of road tunnels with reinforced concrete liners. Transportation Research Record 2672(41):156-164.

[60] Dhamne R, Mishra S, Kumar A, Rao KS (2018) Numerical study of the cross-sectional shape of shallow tunnels subjected to impact and blast loading. Journal of Engineering Geology XLIII(1-2):23-37.

[61] Mussa MH, Mutalib AA, Hamid R, Raman SN (2018) Blast damage assessment of symmetrical box-shaped underground tunnel according to peak particle velocity (PPV) and single degree of freedom (SDOF) criteria. Symmetry (Basel) 10(5):1-20.
[62] Goel MD, Verma S, Panchal S (2020) Effect of internal blast on tunnel lining and surrounding soil. Indian Geotechnical Journal https://doi.org/10.1007/s40098-020-00451-1.

[63] Mandal J, Agarwal AK, Goel MD (2020) Numerical modeling of shallow buried tunnel subject to surface blast loading. Journal of Performance of Constructed Facilities 34(6):04020106.

[64] Kamal I (2008;) Behavior of tunnel with concrete lining subjected to underground explosion in rock media. International Conference on Civil and Architectural Engineering 7(7):135-147.

[65] Richard Liew JY, Wang TY (2011) Novel steelconcrete-steel sandwich composite plates subject to impact and blast load. Advances in Structural Engineering 14(4):673-688.

[66] Samiee A, Amirkhizi A V., Nemat-Nasser S (2013) Numerical study of the effect of polyurea on the performance of steel plates under blast loads. Mechanics of Materials 64:1-10.

[67] Tiwari R, Chakraborty T, Matsagar V (2014) Dynamic analysis of underground tunnels subjected to internal blast loading. $11^{\text {th }}$ World Congress on Computational Mechanics (WCCM $\mathrm{XI}), 5^{\text {th }}$ European Conference on Computational Mechanics (ECCM V), $6^{\text {th }}$ European Conference on Computational Fluid Dynamics (ECFD VI).

[68] Verma AK, Jha MK, Mantrala S, Sitharam TG (2017) Numerical simulation of explosion in twin tunnel system. Geotechnical and Geological Engineering 35(5):1953-1966.

[69] Shin JH, Moon HG, Chae SE (2011) Effect of blast-induced vibration on existing tunnels in soft rocks. Tunnelling and Underground Space Technology 26(1):51-61.

[70] Li X, Li C, Cao W, Tao M (2018) Dynamic stress concentration and energy evolution of deepburied tunnels under blasting loads. International Journal of Rock Mechanics and Mining Sciences 104:131-146.

[71] Zaid M, Sadique MR (2020) The response of rock tunnel when subjected to blast loading: Finite element analysis. Engineering Reports 3(2):1-11.

[72] Li C, Li X (2018) Influence of wavelength-totunnel-diameter ratio on dynamic response of underground tunnels subjected to blasting loads. International Journal of Rock Mechanics and Mining Sciences 112: 323-338.

[73] Sevim B, Toy AT (2020) Blasting Response of a Two-Storey RC Building Under Different Charge 
Weight of TNT Explosives. Iranian Journal of Science and Technology-Transactions of Civil Engineering. 44(2):565-577.

[74] Senthil K, Pelecanos L, Rupali S (2020) Prediction of damage intensity of reinforced concrete tunnels and soil against blast loading. In: 10th International Symposium on Geotechnical Aspects of Underground Construction in Soft Ground, University of Cambridge, 29 June-01 July 2020, UK (Postponed).

[75] Ata A, Nabil M, Hassan S, Nawar M (2021) Numerical analysis of underground tunnels subjected to surface blast loads. Frattura ed Integrita Strutturale 15(55):159-173.

[76] Mandal J, Goel M, Agarwal A. Numerical modeling of tunnel subjected to surface blast loading. In: Saha SK, Mukherjee M (eds) Recent Advances in Computational Mechanics and Simulations Lecture Notes in Civil Engineering (Volume 1), Springer, Singapore, 2021, pp. 543554.
[77] Toy AT, Sevim B (2017) Numerically and empirically determination of blasting response of a RC retaining wall under TNT explosive. Advances in Concrete Construction 5(5):493512.

[78] Altunisik, AC, Onalan F, Sunca F (2021) Effects of concrete strength and openings in infill walls on blasting responses of RC buildings subjected to TNT explosive. Iranian Journal of Science and Technology-Transactions of Civil Engineering https://doi.org/10.1007/s40996-020-00563-x. 